\title{
A METHOD OF MEASURING REFLEX TIMES APPLIED IN SCIATICA AND OTHER CONDITIONS DUE TO NERVE-ROOT COMPRESSION
}

\author{
BY \\ DONALD S. MALCOLM \\ From Departments of Physiology and of Neurosurgery, Otago University, \\ and the Dunedin Hospital, New Zealand
}

It is well known that in sciatica and other clinical conditions resulting from compression of a nerve root by a prolapsed intervertebral disc, disturbances of the tendon reflexes may occur. In sciatica, for instance, diminution or even absence of the ankle jerk is a common finding (Falconer, McGeorge, and Begg, 1948). Sometimes, however, this disturbance is slight and cannot readily be shown by the ordinary clinical tests. This investigation was therefore undertaken to assess the slighter degrees of impairment, and to elucidate its mechanism.

The knee jerk and the ankle jerk are each a true reflex involving only a monosynaptic pathway (Lloyd, 1943). The functional unit of reflex activity in skeletal muscle is, of course, the motor unit (Denny-Brown, 1929). It consists of a group of 100 or more contiguous muscle fibres innervated by a single motor neurone, which by its terminal branches, sends a nerve filament to the end-plate region of each of these muscle fibres (Clark, 1931 ; Weddell, Feinstein, and Pattle, 1944). When a whole muscle is stimulated reflexly, as when its tendon is stretched, its response is usually a submaximal motor twitch, for only some of the motor units respond, although they do so synchronously and once only. A brisk reflex response represents more motor units contracting than in the diminished reflex response. Sirce the motor units contract synchronously, and each in contracting contributes a small action potential, the sum of these action potentials is an index of the number of motor units involved in the reflex response. Thus the deflection recorded on the oscillograph gives a relative measure of the voltage, and can be used to compare one tendon reflex with the corresponding reflex of the opposite limb. In the present investigation, therefore, the oscillograph was used $(a)$ to obtain the conduction time of tendon reflexes, $(b)$ the conduction time past the compressed segment of a nerve root, and (c), within these limitations, a quantitative measure of the responses.

\section{Methods of Investigation}

Timing of Tendon Reflexes.-The reflex time was measured by an apparatus employing a speciallyconstructed percussion-hammer, surface electrodes placed over the muscle, and a double-beam oscillograph with a suitable amplifier to record the muscle response and also the time interval elapsing after the blow. All recordings were made in a shielded room. Button electrodes were chosen in preference to concentric needle electrodes, as they allow numerous points on the muscle to be examined without such discomfort as is caused by the intramuscular insertion of a needle electrode (Adrian and Bronk, 1929). In order to lower the electrical resistance of the skin, the surface electrodes with the concavity of each filled with electrode jelly were sealed over a small scratch (Richter, 1926). In this way an electrical resistance of less than $1,500 \mathrm{ohms}$ was always obtained between any two electrodes. One electrode was placed over the appropriate muscle. The other was sealed to an inactive zone, for example, the tendon, or, what was found to be even more satisfactory, a bony point on the opposite limb. The electrical resistance of this arrangement was found to be less than that of a saline pad used as the indifferent electrode.

The percussion hammer was constructed of halfinch brass tubing in the form of a " $T$ " piece (Fig. 1). The tubing acted as an electrical shield to the contact points situated within the head of the hammer, and all the necessary wiring was led from these contact points to the apparatus by means of shielded flex. A wooden piston, fitting loosely in one end of the head, was shaped to act as the striking edge of the hammer. The other end of this wooden piston rested against the metal contact 


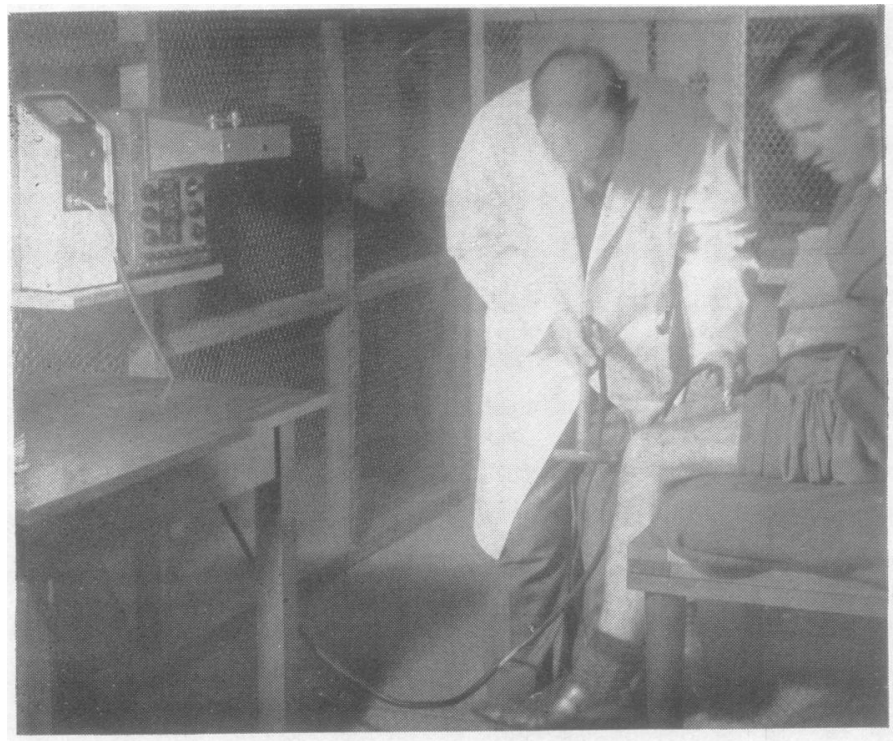

FIG. 1.-The interior of the screened room. The oscilloscope and amplifiers are on the left.

maker, and was adjusted so that any weight on the striking edge made an electrical contact, which triggered the sweep of the oscillograph.

One beam of the oscillograph was used for recording the muscle response, the other as a time marker recording 2 millisecond intervals. In order that the resting fluorescence of the oscillograph should not blur the photographic film, the resting position of the spots was placed on the extreme right, well off the fluorescent screen. The contacts in the head of the percussion hammer, when closed, caused the spot to fly across in $0.1 \mathrm{msec}$. to a position at the left of the screen. The spot then immediately returned to the right side at a slower and uniform speed, taking $50 \mathrm{msec}$. to complete the traverse. The fly-across was so fast that it left no trace on the photographs. The first evidence of the spot photographically and visually was obtained as it turned about on its slower return, and the records were all read from this point. The delay of $0.1 \mathrm{msec}$. in the beginning of the traverse was thus insignificant.

In interpreting the results, the muscle action potential was taken as indicating the arrival of the volley of nerve impulses at the muscle end-plates. Eccles and O'Connor (1939) have shown that after the arrival of the nerve impulse at the end-plates the muscle impulse is propagated down the muscle fibre at a speed of only 3 to 5 metres per second, and it precedes the contraction wave by about 1 msec. (Snyder, 1936). Thus a serious error would arise in the timing of the reflex if the muscle action potential were picked up anywhere other than at the end-plate. This delay in conduction within a muscle is partly compensated by the branching of the nerve and the dispersal of its axons within the muscle, and optimum results can usually be obtained if the electrode is placed over the belly of the muscle close to the point of nerve entry.

Where actual reflex times are stated in this paper they represent the average of at least six readings from one point on a muscle : the experimental error of the method was not greater than $\pm 0.5 \mathrm{msec}$.

Timing of Nerve Conduction Rates at Operation.-In some patients with nerve-root compression, whose tendon jerks had been timed pre-operatively, the conduction time in the affected nerve-root from the cauda equina to the muscle was measured at the operation undertaken for removal of the compressing lesion, and contrasted with the conduction time of the same nerve-root on the opposite side. Each patient was an example of compression of both ventral and dorsal nerves at $a^{2} \vec{T}$ point immediately lateral to the theca by a prolapsec 8 intervertebral disc. In each a laminectomy of onE or two vertebrae was performed, but before the site of compression was disturbed the theca was opened One or two nerve-roots on each side within the theca, including of course the root proximal to the site of compression, as well as its fellow of the opposite side as a control, were then isolated proximal to the lesion. Each nerve-root in turn was then stimulated submaximally with a single shock. For this purpose a sterilized triple-hook electrode was employed, the central electrode being the cathode, the outer two being anodes. The resulting response in the muscle was again recorded by surface electrodes, applied as described earlier. The whole apparatus was so arranged that a single stimulus could be given to the nerve root by a thyratron valve, and this stimulus also triggered the sweep of the recording oscillograph. For this part of the work the sweep speed of the beam was increased approximately two and a half times and thus the accuracy of the recordings was enhanced. This was made possible by the fact that the actual time interval to be measured was less than half that required for the reflex times: the longest reflex time recorded was $44 \mathrm{msec}$. compared with a of maximum of $19.1 \mathrm{msec}$. in the direct stimulation $N$ experiments. The experimental error in this second 
portion of the work was not greater than $\pm 0.25 \mathrm{msec}$. In Table VI, which gives the actual times recorded, the results are stated as an average of at least six recordings made from each point on the muscle concerned. For the fourth lumbar root (L.4) the record was best obtained from the rectus femoris muscle, for the L.5 root from the tibialis anticus muscle or the extensor brevis digitorum muscle, and for the S.1 root, the gluteus maximus muscle, the soleus muscle, or the gastrocnemei muscles.

\section{OBSERVATIONS}

\section{Normal Reflexes}

Figs. 2 (knee jerk) and 3 (ankle jerk) show a normal reflex tracing. A indicates the moment that the hammer hit the tendon (less $0.1 \mathrm{msec}$. for the fly-across), and $B$ indicates the onset of the muscle action potential CD. The initial negative deflection is marked $\mathrm{C}$, and the positive deflection, D. The reflex time is represented by the distance $\mathrm{AB}$, being the time of horizontal travel of the beam before it is deflected vertically to form the initial negative wave of the muscle action potential. In the two figures shown it measured 22 msec. and $42 \mathrm{msec}$. respectively.

Typical reflex times obtained from an adult $5 \mathrm{ft}$. 6 in. in height were as follows :-

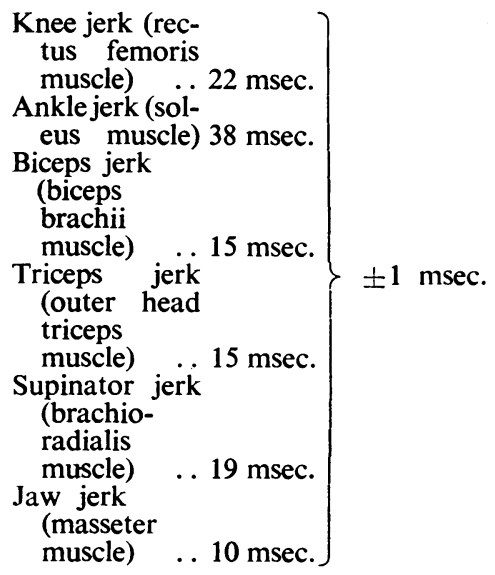

\section{Factors Influencing Reflex Times}

As the reflex time is dependent on many factors, a study was made of the more important of these to see how they might influence the record.
Position of Electrodes in Relation to Muscle.By placing electrodes at various points over the whole of a muscle, it proved possible to map the muscle in terms of the times of arrival of the muscleaction potential wave. Figs. 4 and 5 illustrate the observations which were made. It can be seen that delays of up to $4 \mathrm{msec}$. occurred in the reflex time of the knee jerk to different parts of the quadriceps muscle (Fig. 4). The earliest development of negativity takes place near the point of entry of the main nerve trunk, and over a considerable portion of the muscle it begins slightly later than this by the interval required by the terminal branches of the nerve to distribute the exciting nerve impulses throughout the whole muscle. Consequently, when comparing one reflex with its fellow of the other side, the recording electrodes should be placed at symmetrical points, and preferably close to the point of nerve entry. When the recording electrode is over muscle fibres some distance from the motor end-plates, there is an initial positive deflection which reverses to negative as the impulses in the

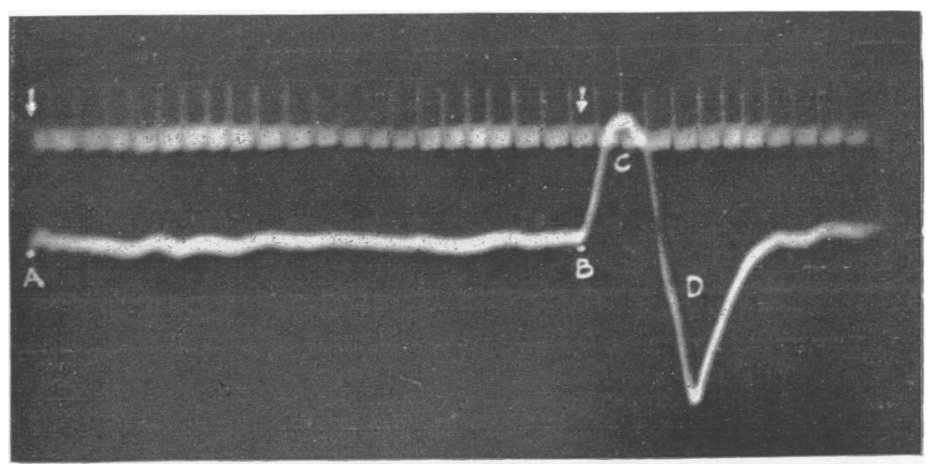

FIG. 2.-Normal reflex (knee jerk). Tracing from rectus femoris muscle. Reflex time : $22 \mathrm{msec}$. Time tracing in $2 \mathrm{msec}$. intervals.

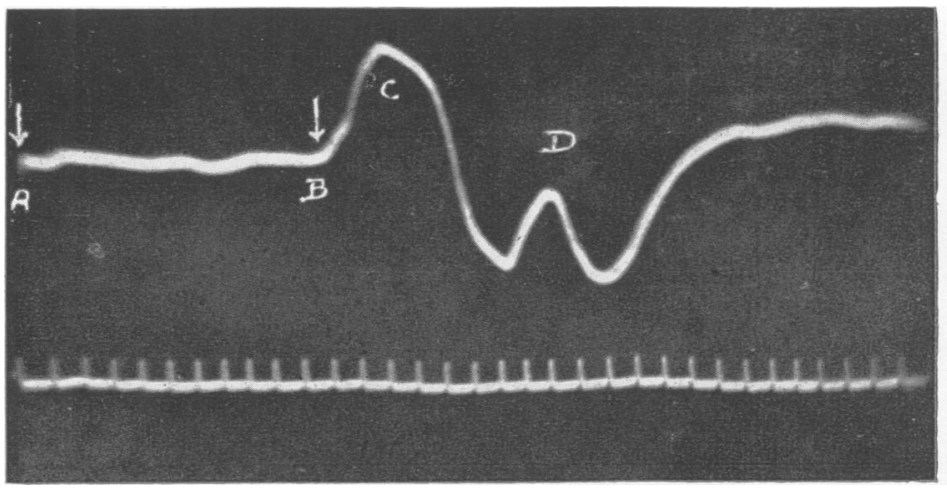

Fig. 3.-Normal reflex (ankle jerk). Tracing from soleus muscle. Reflex time : $42 \mathrm{msec}$. Time tracing in $2 \mathrm{msec}$. intervals. 
muscle fibre propagate up to the electrode (Eccles and O'Connor, 1939). The recorded potential then has a triphasic configuration. Over the gastrocnemius muscle these triphasic potentials are frequently observed (Fig. 5). Presumably this is attributable to the arrangement of the muscle fibres, since the great majority of the end-plates lie deep within the muscle.

Strength of Blow.-The strength of the blow, provided it was adequate to give a visible response in the muscle, was found to have little bearing upon the reflex time. With very soft taps the reflex time was prolonged, but this was more apparent than real, for the point of onset of the initial negative deflection became more difficult to determine. Provided there was a sharp deflection at the onset of the action potential, reflex times did not vary more than $\pm 0.5 \mathrm{msec}$.

Reinforcement.-By using reinforcement (locking both hands together and attempting to pull them apart while the tendon is being struck) the only

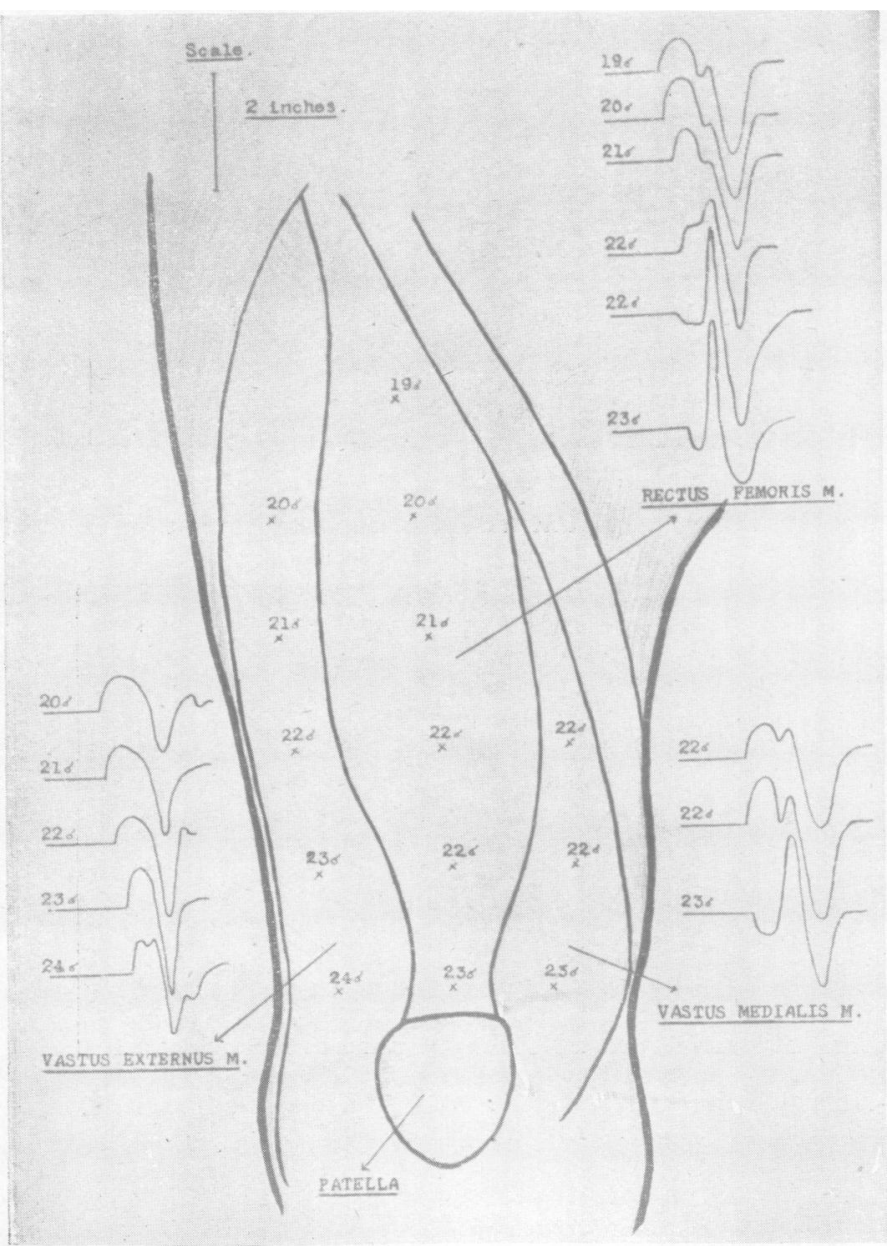

change was an increase in the voltage developed ; the reflex time remained the same. This method was often used with advantage because, with the larger potential developed, the point of onset of the response was sharper and more clearly defined.

TABLE I

REFLEX TIMES FOR ANKLE JERK WITH VARYING DEGREE OF TENSION ON THE TENDO ACHILLIS

\begin{tabular}{c|c|c|c}
\hline $\begin{array}{c}\text { Weight } \\
\text { Applied } \\
\text { (lb.) }\end{array}$ & $\begin{array}{c}\text { Readings* } \\
\text { (msec.) }\end{array}$ & $\begin{array}{c}\text { Voltage } \\
\text { Response } \\
\text { (mv.) }\end{array}$ & Comment \\
\hline 0 & $34.5 \pm 0.5$ & 0.05 to 0.3 & $\begin{array}{c}\text { Voltage response } \\
\text { too erratic }\end{array}$ \\
\hline$\frac{1}{2}$ & $34.5 \pm 1.0$ & 0.1 to 0.2 & $\begin{array}{c}\text { Reflex time vari- } \\
\text { able }\end{array}$ \\
\hline 1 & $34.5 \pm 0.5$ & 0.1 to 0.2 & $\begin{array}{c}\text { Consistent re- } \\
\text { sults and } \\
\text { adopted as } \\
\text { standard }\end{array}$ \\
\hline
\end{tabular}

* Average of six.

Tension of the Tendon.-Alterations in the tension on the tendon will provoke variations in the muscle voltage, but the reflex time remains fairly constant (Table I). It is there fore advisable to adopt standard postures fo the limbs when recording. The knee jerk was always taken with the patient sitting and the legs hanging freely over the edge. For the ankle jerk the patient lay in the prone positio with his feet out over the end of the coucho and, by means of a $1 \mathrm{lb}$. lead weight and pulley, the tension was applied by a cloth band around the region of the metatarsal heads (Fig. 6).

Height of the Patient.-By using comparable points on the rectus femoris muscle in a series of 24 volunteers, both children and adults, a graph (Fig. 7) was constructed correlating the reflex time of the knee jerk and the height of the subject. In this graph, the findings of Whitehorn and Lundholm (1930) are shown for comparison. The graph shows that the reflex time is roughly proportional to the height of the subject.

Sphere of Pick-up of Surface Electrodes.In order to determine how much the electrical

Fig. 4.-Outline drawing of right quadriceps muscle showing at various points the time of arrival of the muscle action potential and response to a blow on the patella tendon. The configuration of the muscle action potential is shown in the three groups of tracings.

\section{$\vec{v}$}

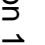
T1 $\frac{1}{2}$ $\overrightarrow{0}$ . 
record is influenced by voltage changes arising in muscle at a distance from the site of the surface electrode, a comparison was made between the responses obtained with the surface electrode and those obtained with a concentric needle electrode. The sphere of pick-up of the latter has been determined by Weddell, Feinstein, and Pattle (1944) as approximately $2 \mathrm{~cm}$. from the tip. That the surface electrode has a sphere of pick-up which is no greater, at least in the longitudinal axis of the muscle, is suggested by the fact that agreement in reflex times to within fractions of a millisecond was obtained by either method. Therefore a method of recording muscle action potentials by means of surface electrodes is deemed valid.

Speed of Conduction of Impulses through Nerves.-Variations in the speed of conduction in human motor nerve fibres under physiological conditions were investigated because they are a major factor in the conduction time of any tendon jerk. For this purpose, separate experiments involving the ulnar nerve and the hypothenar muscles were devised (Table II). In several normal adults the ulnar nerve was stimulated percutaneously at three points : A, immediately below the anterior axillary fold ; $\mathrm{B}$, behind the internal epicondyle of the humerus; and $\mathrm{C}$, at the wrist immediately proximal to the pisiform bone. The muscle recording electrode was placed at a central point over the hypothenar eminence. The time taken between stimulation at each of these points and the appearance of the muscle-action potential was measured. $B y$ subtraction the time taken by the nerve impulse over the distances $\mathrm{AB}$ and $\mathrm{BC}$ was obtained, and the conduction velocity was calculated.

It can be seen that in one subject, in whom five separate observations were made at different times, variations in the conduction rate of between 52 and 70 metres per second were observed. These variations were probably accounted for by differing temperatures of the limb, for in Table II(b) the temperature factor was controlled, and when the limb was warmed above the usual level the conduction velocity increased from 63 to 79 metres per second. Presumably the velocity at normal body temperatures is normally between 60 and 70 metres per second, and this was also suggested in another experiment when a length of human nerve (branch of the internal popliteal nerve to the tibialis posticus

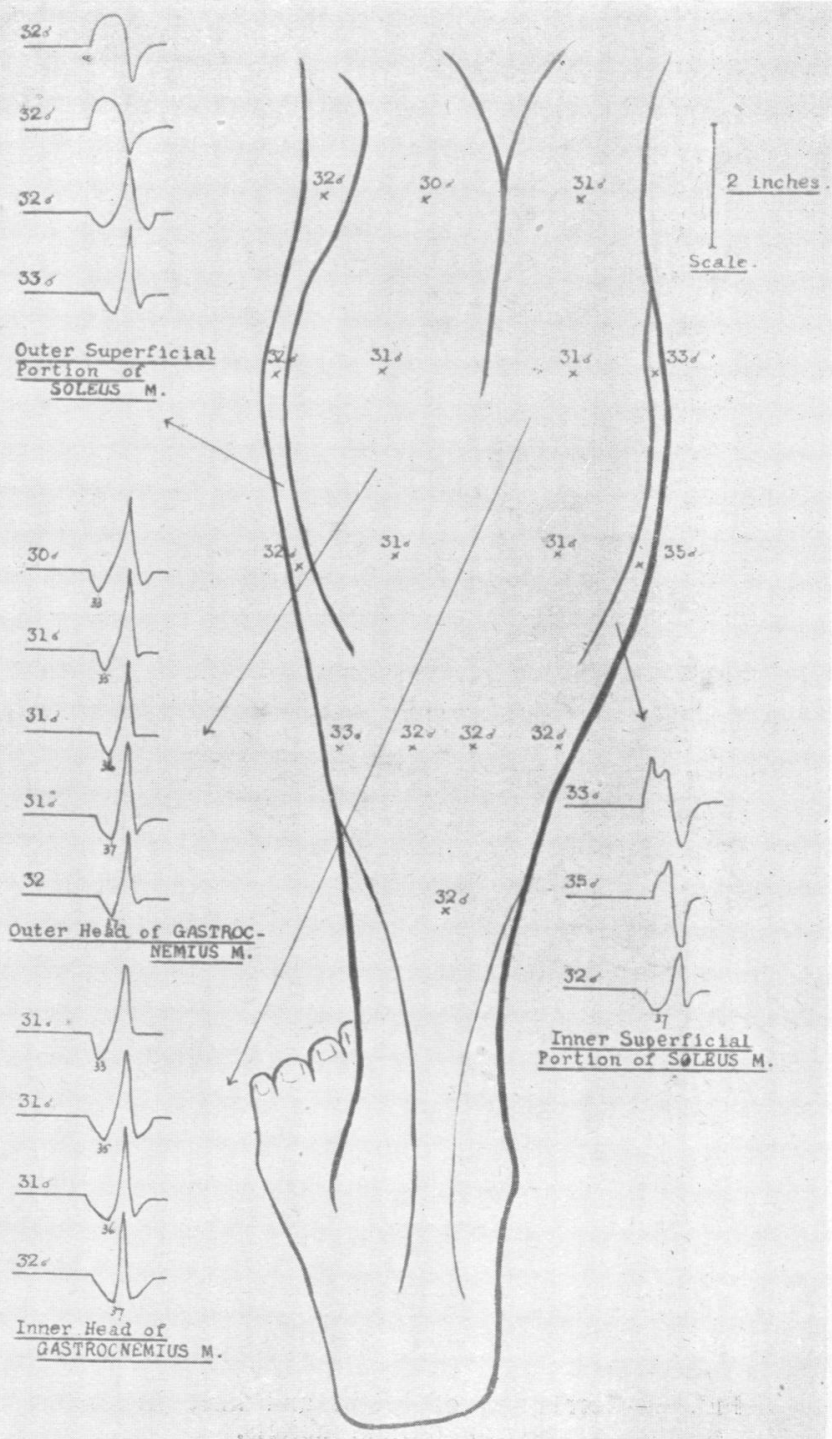

Fig. 5.-Outline drawing of left soleus and gastrocnemei muscles showing at various points the time of arrival of the muscle action potential in response to a blow on the Achilles tendon. The configuration of the muscle action potential is shown in the four groups of tracings.

muscle) obtained from a freshly amputated limb was kept alive for two hours. The maximum speed of conduction recorded under these conditions which were as nearly physiological as possible, was 60 metres per second.

Effect of Pyramidal, and Other Lesions.-From present-day knowledge of the tendon reflexes it would not be expected that lesions of the pyramidal, extra-pyramidal, or cerebellar pathways would 


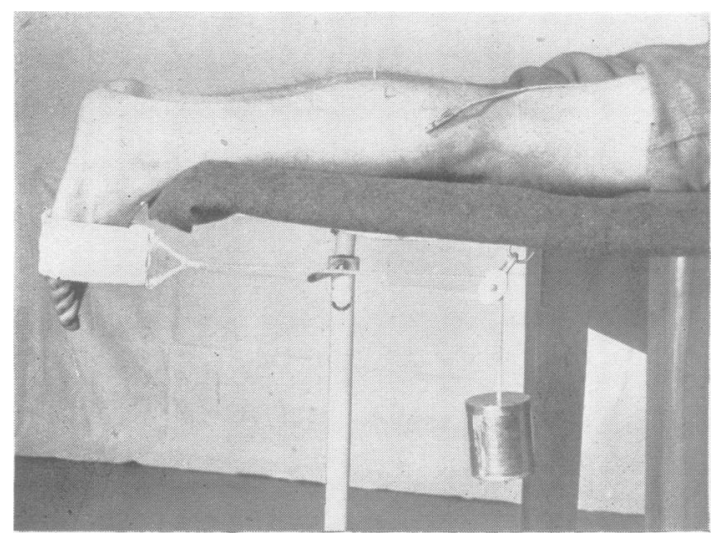

FIG. 6.-The standard method of obtaining tension on the tendo Achillis for eliciting the ankle jerk.

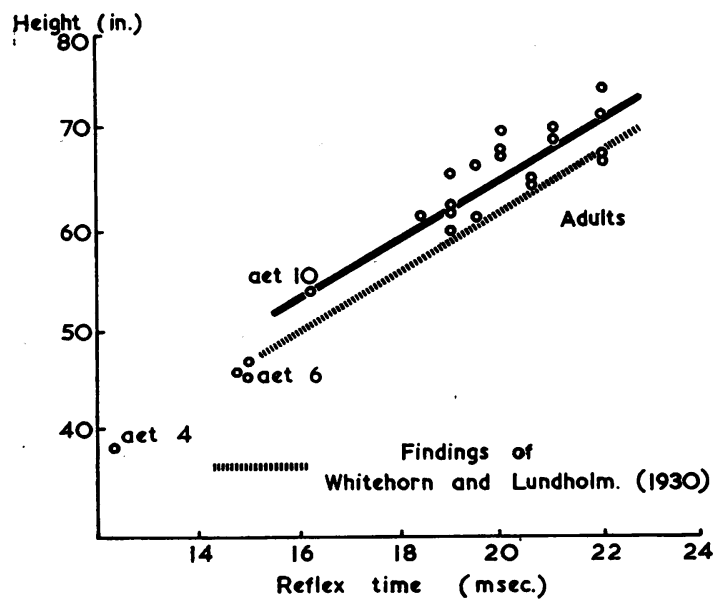

Fig. 7.-Correlation of height and knee jerk reflex time in normal subjects.

appreciably influence the time relations of the reflex. The series of cases presented in Table III supports this view. Similarly, no appreciable alteration in reflex conduction times was noted in patients suffering from a variety of endocrine disorders with metabolic upsets (Table IV).

Voltages Developed.-The voltages developed varied in normal subjects with moderately brisk reflexes ; the present apparatus usually registered a negative deflection of approximately $0.3 \mathrm{mv}$. When the reflexes were exaggerated, as in an upper motor neurone lesion, the voltage obtained by a maximal blow might rise to the vicinity of $1.0 \mathrm{mv}$., whereas in diminished reflexes the muscle voltage seemed correspondingly less. As a quantitative measure of
TABLE II (A)

STIMULATION OF ULNAR NERVE AND TIME OF ONSET OF ACTION POTENTIAL IN THE HYPOTHENAR MUSCLES

\begin{tabular}{c|c|c|c}
\hline Subject & $\begin{array}{c}\text { Length of Ulnar } \\
\text { Nerve Measured } \\
\text { (cm.) }\end{array}$ & $\begin{array}{c}\text { Time } \\
\text { Taken } \\
\text { (msec.) }\end{array}$ & $\begin{array}{c}\text { Velocity } \\
\text { (metres } \\
\text { per sec.) }\end{array}$ \\
\hline D.M. & 14 (arm) & $2 \cdot 0$ & 70 \\
P.S. & 22 (arm) & $3 \cdot 2$ & 69 \\
D.M. & 15 (arm) & $2 \cdot 4$ & 63 \\
D.M. & 27 (forearm) & 4.9 & 55 \\
D.M. & 27 (forearm) & $5 \cdot 2$ & 52 \\
D.M. & 27 (forearm) & $5 \cdot 1$ & 53 \\
W.D. & 27 (forearm) & $4 \cdot 5$ & 60 \\
A.C. & 26 (forearm) & 4.9 & 56 \\
\hline
\end{tabular}

TABLE II (B)

STIMULATION OF ULNAR NERVE AND CONDUCTION VELOCITY UNDER CONTROLLED TEMPERATURE

\begin{tabular}{l|c|c|c}
\hline Subject & $\begin{array}{c}\text { Length } \\
\text { of Ulnar } \\
\text { Nerve* } \\
\text { (cm.) }\end{array}$ & $\begin{array}{c}\text { Skin } \\
\text { Temperature } \\
\left({ }^{\circ} \mathrm{C}\right)\end{array}$ & $\begin{array}{c}\text { Conduction } \\
\text { Velocity } \\
\text { (metres per sec.) }\end{array}$ \\
\hline D.M. & 15 & 25 & 63 \\
\hline
\end{tabular}

Arm at room temperature, then incubated for half an hour a $37^{\circ}$ C. Ulnar nerve stimulated as in Table IIa.

the reflex response, however, the eye was approxt mately as sensitive, for the apparatus could no register a response when there was an absent tendo reflex to the naked eye.

In Fig. 8 a quantitative comparison has been made between the voltage developed by reflex response and the response obtained by direct stimulation of the nerve root. It should be noted that, although the voltage developed by direct stimulation is very much greater than in the reflex, this was still not a maximal stimulation of the nerve root.

\section{Nerve Root Compression}

Conduction Time of Tendon Reflexes.-Having thus shown the constancy of the conduction times in normal subjects, we were in a position to evaluate the effects of unilateral nerve-root compressions, such as sciatica due to the prolapse of the intervertebral disc. Eleven patients were investigated (Table V), seven of whom had purely unilateral signs and symptoms, while the remainder had evidence of bilateral lesions and must therefore be considered separately. All these patients complained of severe, intractable pain which had not yielded to conservative management. 
TABLE III

EFFECT OF PYRAMIDAL AND OTHER LESIONS ON REFLEX TIMES

\begin{tabular}{|c|c|c|c|c|c|}
\hline \multirow[b]{2}{*}{ Condition } & \multirow[b]{2}{*}{ Patient } & \multirow[b]{2}{*}{ Pathology } & \multirow[b]{2}{*}{ Reflex } & \multicolumn{2}{|c|}{ Reflex Times } \\
\hline & & & & $\begin{array}{c}\text { Right } \\
\text { (Msec.) }\end{array}$ & $\begin{array}{c}\text { Left } \\
\text { (Msec.) }\end{array}$ \\
\hline \multirow[t]{4}{*}{ Pyramidal lesions } & A & Right hemiplegia & $\begin{array}{l}\text { Knee jerk } \\
\text { Supinator } \\
\text { Triceps }\end{array}$ & $\begin{array}{l}21 \\
19 \frac{1}{2} \\
14 \frac{1}{2}\end{array}$ & $\begin{array}{l}21 \\
19 \frac{1}{2} \\
15\end{array}$ \\
\hline & B & Right hemiplegia & Ankle jerk & 37 & 37 \\
\hline & $\mathrm{C}$ & Right hemiplegia & Supinator & $19 \frac{1}{2}$ & 19 \\
\hline & D & Cerebral diplegia & Ankle jerk & 32 & 32 \\
\hline \multirow[t]{3}{*}{ Cerebellar lesions } & $\mathrm{E}$ & Left acoustic nerve tumour & $\begin{array}{l}\text { Knee jerk } \\
\text { Ankle jerk }\end{array}$ & $\begin{array}{l}21 \\
42\end{array}$ & $\begin{array}{l}21 \\
42\end{array}$ \\
\hline & F & Right acoustic nerve tumour & Knee jerk & $19 \frac{1}{2}$ & $19 \frac{1}{2}$ \\
\hline & G & Tumour left cerebellar lobe & Knee jerk & $20 \frac{1}{2}$ & $20 \frac{1}{2}$ \\
\hline Extrapyramidal lesions & $\mathrm{H}$ & Post-encephalitic Parkinsonism & Knee jerk & $21 \frac{1}{2}$ & $21 \frac{1}{2}$ \\
\hline Normal adults as controls & & & $\begin{array}{l}\text { Knee jerk } \\
\text { Ankle jerk }\end{array}$ & & \\
\hline
\end{tabular}

TABLE IV

EFFECT OF PYRAMIDAL AND OTHER LESIONS ON REFLEX TIMES IN ENDOCRINE DISORDERS WITH METABOLIC UPSETS

\begin{tabular}{|c|c|c|c|c|c|c|}
\hline \multicolumn{3}{|l|}{ Condition } & \multirow{2}{*}{$\frac{\text { Patient }}{\text { I }}$} & \multirow{2}{*}{$\begin{array}{c}\begin{array}{c}\text { B.M.R. } \\
(\%)\end{array} \\
+40\end{array}$} & \multirow{2}{*}{$\begin{array}{c}\begin{array}{c}\text { Measured } \\
\text { Reflex Time } \\
\text { (Msec.) }\end{array} \\
\text { Knee jerk } 19\end{array}$} & \multirow{2}{*}{$\begin{array}{l}\text { Calculated Reflex Time } \\
\text { from Correlation with } \\
\text { Height (Msec.) }\end{array}$} \\
\hline Thyrotoxicosis .. & .. & . & & & & \\
\hline & & & $\mathbf{J}$ & +55 & Knee jerk 22 & 21 \\
\hline & & & $\mathbf{K}$ & +46 & Ankle jerk 36 & 36 \\
\hline Hypopituitarism .. & .. & .. & $\mathrm{L}$ & -20 & Knee jerk 20 & 21 \\
\hline Fröhlich's syndrome & .. & .. & $\mathbf{M}$ & Normal & Knee jerk 19 & 19 \\
\hline
\end{tabular}

In the group with purely unilateral lesions it was found that five of the seven patients showed delay of 1 to 4 msec. in the reflex time on the affected side. (In four of these there was a compression of the first sacral nerve-root, and in the fifth compression of the fourth lumbar nerve-root.) There remain two cases in this group, patients I and IV, where no delay in reflex time was recorded; yet from both the clinical investigations and operative findings there is proof that a unilateral lesion existed : in the first instance an L.5 nerve-root, in the second an S.1 nerve-root.

The results from the second group where evidence of bilateral lesions existed, can be analysed as follows : in two instances, patients VIII and XI, clinical evidence of bilateral lesions existed, and the delay in reflex time corresponded to the side giving the more severe symptoms and was in keeping with the operative findings. In the other two cases, patients IX and X, bilateral lesions again existed, but the delay was present on the side which one would have thought, judging from the operative appearances, was now the less compressed. However, in both cases there had been a history of severe pain on the side which was delayed but this pain had since eased; it may well be that these nerve-roots were damaged at this earlier date.

Considering all these results together, it is evident that of the 11 patients investigated seven showed a delay in reflex time which was in keeping with the clinical and operative findings; two others showed no delay when unilateral lesions were found to be 


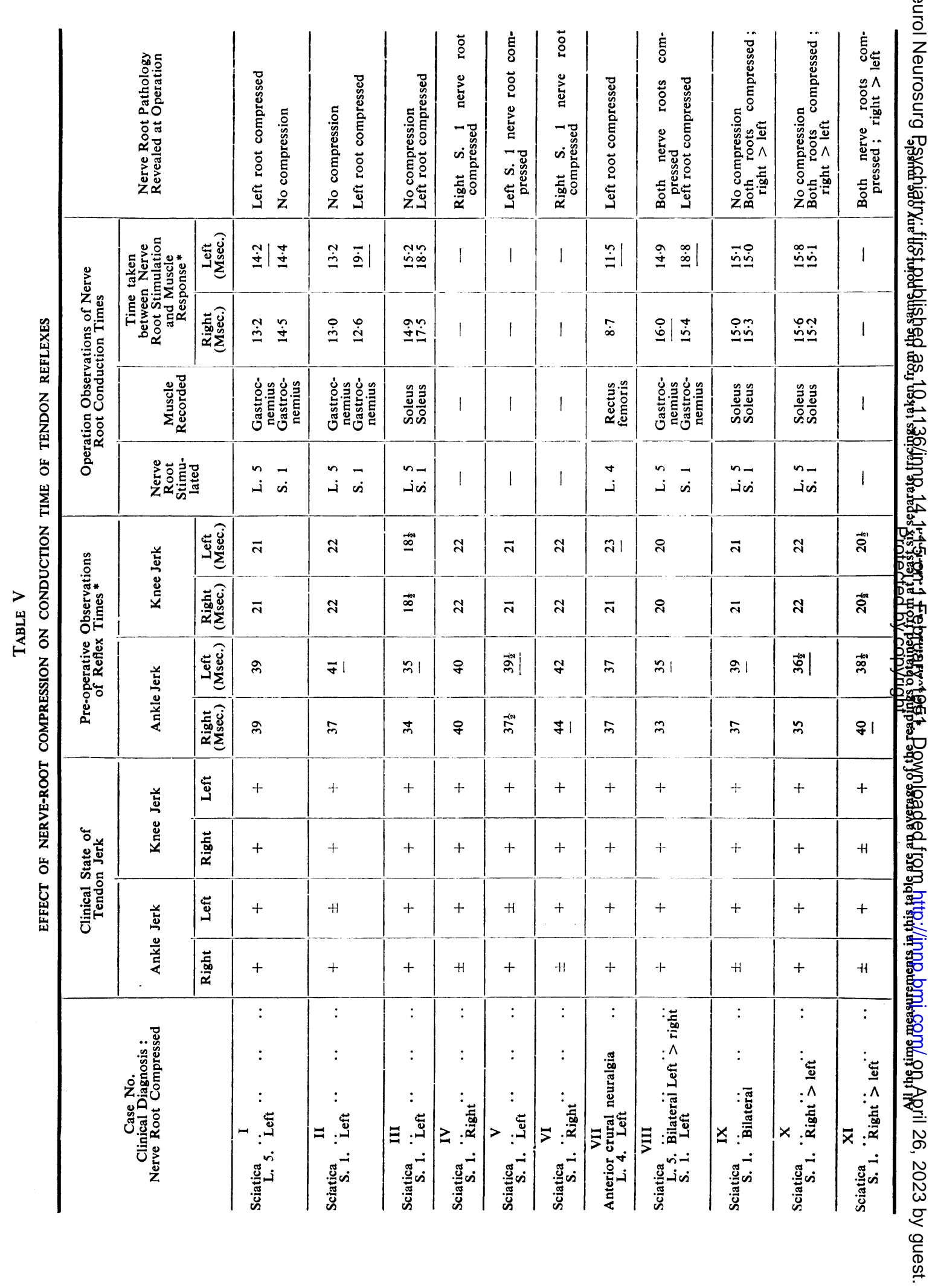




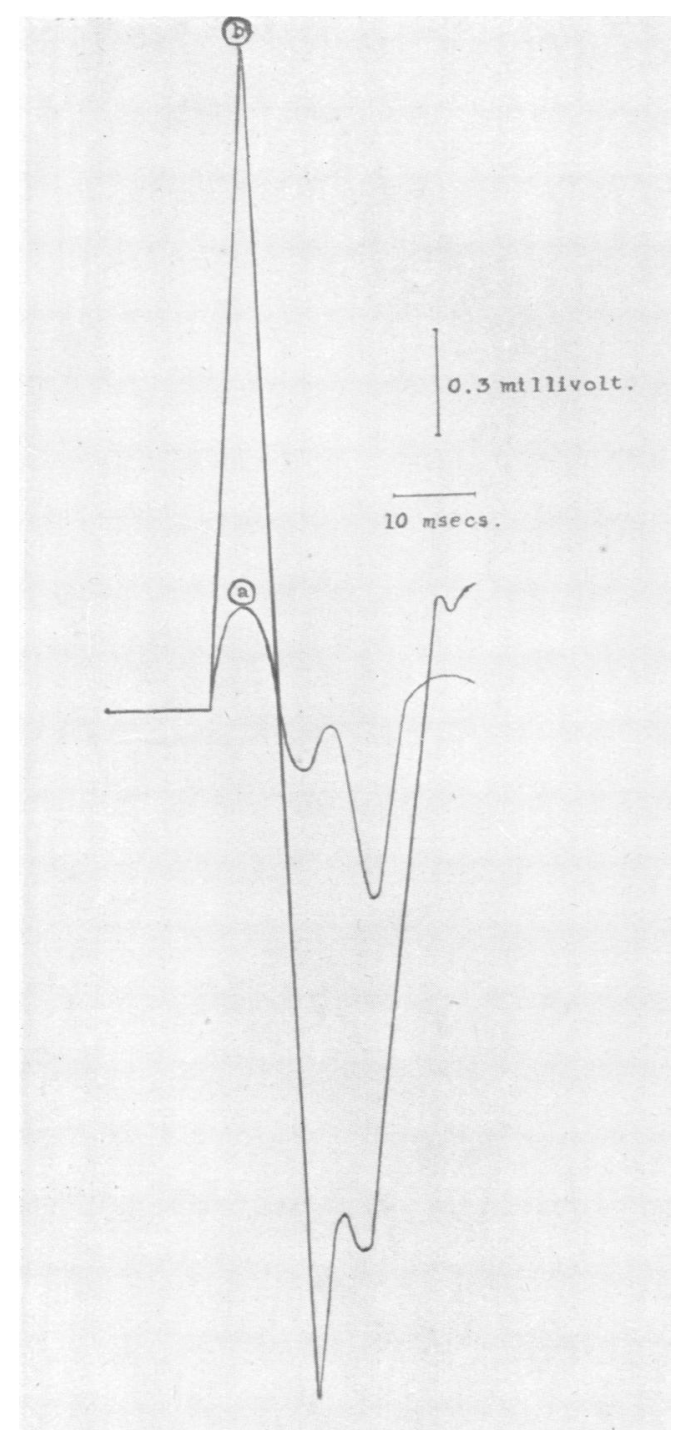

FIG. 8.-Comparison of the voltages developed in the rectus femoris muscle (a) by a blow on the tendon, and (b) by submaximal stimulation of the fourth lumbar nerve root (patient VII).

present by operative investigation, and in the remaining two cases operation revealed bilateral lesions with the more macroscopic nerve-root compression on the side which did not show a delay by the reflex time method.

Further analysis of these cases shows that it is in lesions of the first sacral nerve root that alterations are more consistently obtained. The clinical state of the tendon jerk does not always mirror the delay found in reflex time; there were two instances, patients III and VII, where no visual difference could be detected in the reflexes, and yet delays of 1 and 2 msec. existed, whereas in patient IV there was no delay and yet clinically a marked diminution of the ankle jerk on the affected side. In the two cases where the reflex method gave contradictory results to the clinical and pathological findings bilateral compressions of the first sacral nerve roots were found. Reference will be made again to these two cases, for in neither instance could a delay be demonstrated at operation in the individual nerve roots subserving the ankle jerk.

Conduction Rates Past the Compressed Segment.In seven of the 11 patients in whom the reflex times had been measured pre-operatively an opportunity was taken at operation to measure the conduction rates in the motor root past the compressed segment. This was done according to the method already described, in which by stimulating the individual nerve root within the theca a recording was made of the time taken by a synchronous volley of nerve impulses to travel from above the site of compression down the nerve to the muscle; this was then compared with the conduction time of the normal nerve roots. It can be seen that in five cases there were delays of from $1.0 \mathrm{msec}$. to $6.5 \mathrm{msec}$, in keeping with the pathological findings. In the remaining two cases, both of which had bilateral compression of nerve roots, no delay could be detected when comparing one side with the other; and neither side appears delayed, for the conduction times when compared with controls appear to be within normal limits.

Table VI also shows that there is no correlation between the amount of delay and the clinical assessment of the reflex. Patient III showed the shortest delay of $1.0 \mathrm{msec}$. and the ankle jerks were equal, but patient VIII, with a delay of 3.4 msec., also had no visible alteration of the reflexes. A useful comparison can also be made between the delay recorded by the reflex method and that obtained by direct nerve root stimulation; patient III showed a 1 msec. delay by both methods, while in all of the others the delay was markedly less when the reflex method was used. Thus in patient II, in whom the direct stimulation method gave a $6.5 \mathrm{msec}$. delay, the reflex time delay was only $4 \mathrm{msec}$

\section{Discussion}

This study has shown how constant the reflex time is in health and disease, being unaffected in metabolic disturbances, and in lesions of the pyramidal, extrapyramidal, and cerebellar tracts. The fact that a delay frequently occurs in sciatica 
on the side of the symptoms must therefore be of significance, even though it does not occur in all cases.

These delays in the reflex time result from the slowing of the passage of nerve impulses through the region of the compressed nerve-root. The slowing of conduction is more marked and more constant when the actual nerve-root affected is investigated than when the appropriate tendon jerk is examined. This is because more than one root enters into the reflex, and as the second and third roots might be normal the delay is less apparent. Tinel (1917), for instance, showed that the knee jerk is not usually abolished unless there is a lesion affecting the third and fourth lumbar segments of the cord or their nerve-roots. Therefore, when the fourth lumbar nerve-root is compressed, the reflex pathway is still unaffected in the third lumbar segment. Again, the ankle jerk is not usually lost after fifth lumbar nerve-root compression, but only after compression of the first sacral nerve-root, for in this case it is the latter nerve-root which is the principal root concerned.

The experimental results show that it is in the unilateral lesions of the first sacral nerve-root that a delay in the ankle jerk reflex time is most constantly found and can be demonstrated even with greater certainty by direct stimulation of the nerveroot above the level of the lesion. The clinical assessment of a diminished tendon reflex does not always run pari passu with the delay in the conduction time.

\section{Summary}

The reflex time of both the ankle jerk and knee jerk in normal adults has been found to be constant.
The application of this method of measuring reflex times to the study of nerve-root compression is described. A longer reflex time has been found on the affected side in patients with lesions which produce unilateral nerve-root compression. Evidence is presented which suggests that in these patients there is a slowing of the speed of nerve-impulse conduction past the compressed segment of nerveroot.

This work was made possible through a grant by the Medical Research Council of New Zealand. I wish to express my indebtedness to Mr. M. A. Falconer of the Neuro-Surgery Department, Dunedin Public Hospital, for his great help and kindly encouragement while this work was being done in his Department ; to Prof. J. C. Eccles for the facilities given me in the Electronics Laboratory, Physiology Department, Otago Medical School, Dunedin; and to Mr. E. E. Suckling, who constructed the electrical equipment.

\section{REFERENCES}

Adrian, E. D., and Bronk, D. W. (1929). J. Physiol., Lond., 67, 119.

Clark, D. A. (1931). Amer. J. Physiol., 96, 296.

Denny-Brown, D. (1929). Proc. roy. Soc. B., 104, 252.

Eccles, J. C., and O'Connor, W. J. (1939). J. Physiol., 97, 44.

Falconer, M. A., McGeorge, M., and Begg, A. C. (1948) Journal of Neurology, Neurosurgery and Psychiatry, $11,13$.

Lloyd, D. P. C. (1943). J. Neurophysiol., 6, 317.

Richter, C. P. (1926). J. Amer. med. Ass., 87, 1300.

Snyder, C. D. (1936). Amer. J. Physiol., 115, 441.

Tinel, J. (1917). "Nerve Wounds", trans. by Rothwell, F. London.

Weddell, G., Feinstein, B., and Pattle, R. E. (1944). Brain, 67, 178 .

Whitehorn, J. C., and Lundholm, H. (1930) Amer. J. Physiol., 92, 214. 